\title{
Preparation and analysis of a two-components breath figure at the nanoscale
}

\author{
Richard Kofman $^{\mathrm{a}^{*}}$, Marco Allione ${ }^{\mathrm{a}, 1}$, Franck Celestini ${ }^{\mathrm{a}}$, Zahava Barkay ${ }^{\mathrm{b}}$ and Yossi Lereah ${ }^{\mathrm{b}, \mathrm{c}}$ \\ ${ }^{a}$ Laboratoire de Physique de la Matière Condensée, Université de Nice Sophia Antipolis et UMR \\ CNRS N ${ }^{\circ}$ 6622, Parc Valrose, 06108 Nice Cedex 2, France \\ ${ }^{\mathrm{b}}$ Wolfson Applied Materials Research Center, Tel-Aviv University, 69978 Tel-Aviv, Israel \\ ${ }^{\mathrm{c}}$ Department of Physical Electronics, Faculty of Engineering, \\ Tel-Aviv University, 69978 Tel-Aviv, Israel
}

\begin{abstract}
$\underline{\text { Abstract: }}$
Solid/liquid two-components $\mathrm{Ga}-\mathrm{Pb}$ structures in isolated nanometer sized particles have been produced and studied by electron microscopy. Production is based on the breath figure technique and we investigate the way the two components are distributed. We clearly identify two growth regimes associated with the two different ways a $\mathrm{Pb}$ atom incorporates into a Ga nanodrop. Using TEM and SEM, the shape and microstructure of the nanoparticles are studied and the results obtained are in good agreement with the proposed model. The experimental technique used appears to be appropriate to produce $\mathrm{Pb}$ nanocrystals in liquid Ga nano-container.
\end{abstract}

\section{Introduction}

The self-organization of a non-wetting deposit on a substrate is well known in the case of water and certain metals [1-2]. This island growth type is a Volmer-Weber one [2] and the result is named "breath figure" by analogy with the figure which one obtains when breathing on a cold piece of glass. With this growth type, it should be possible to prepare many materials at the nanoscale. The self-organization process leading to a breath figure, based on nucleation-growth and coalescence has been investigated [2] to demonstrate its advantages and limitations: the nanoparticles size distribution can be obtained in a large range of mean sizes with a rather low dispersion (20\% in the best case [2]). The shape of the nanoparticles is generally a truncated sphere and, for what concerns crystals, we observe defects whose density depends on size and temperature [3].

One wonders what could be the shape of a breath figure containing two non-interacting components. Recently, Hagege and Dahmen [4] investigated small $\mathrm{Pb}-\mathrm{Cd}$ inclusions embedded in an aluminum matrix and discussed the resulting microstructure in terms of the relative magnitudes of the two components and matrix interface energies.

In the present work, we have focused our attention on the system of quasi-immiscible elements $\mathrm{Ga}-\mathrm{Pb}$. In this system, gallium is a material with a very low melting temperature $\left(29.78^{\circ} \mathrm{C}\right)$ and undercooling properties [5]; moreover, when dispersed in small particles, its cristallographic phase changes with a melting temperature even lower [5] $\left(-19.4^{\circ} \mathrm{C}\right.$ for the $\delta$ phase). It results that, at room temperature, the $\mathrm{Ga}-\mathrm{Pb}$ nanosystem is such that $\mathrm{Ga}$ is liquid and $\mathrm{Pb}$ solid. Concerning the mutual solubility of both materials, the $\mathrm{Ga}-\mathrm{Pb}$ phase diagram shows that, at room temperature, the mutual solubilities are lower than $10^{-3}$ at $\%$ [6].

In this paper, we report the preparation, the characterization and the growth understanding of

\footnotetext{
${ }^{1}$ Present adress : Italian Institute of Technology, via Morego 30, 16163 Genova, Italy
} 
the first two-components breath figure obtained at the nanoscale. In a first section, we present the experimental set-up used to prepare the alloy nanoparticles. In a second one, we fully analyse the two components breath figure growth and present a simple model to describe it. Finally we discuss the results obtained, especially the agreement found with the model, and dress some conclusions.

\section{Production of breath figures and characterization}

Production of $\mathrm{Ga}-\mathrm{Pb}$ breath figures is done under UHV on dedicated substrates for transmission electron microscopy (TEM) and scanning electron microscopy (SEM):

TEM substrates are copper grids (400 mesh) of diameter $3 \mathrm{~mm}$ covered by an amorphous carbon layer a few nanometers thick (Agar scientific) while for SEM silicon wafers are used. For production, substrates are attached on a controlled temperature stage inside the UHV system. A thin layer of silicon monoxide $\left(\mathrm{SiO}_{\mathrm{x}}\right)$, which is transparent to electrons, is first deposited to get the same substrate on both supports. Crucibles containing $\mathrm{Ga}$ or $\mathrm{Pb}$ are atomic vapour sources. $\mathrm{Ga}$ is then deposited at $50^{\circ} \mathrm{C}$ to obtain a nanodrops breath figure [2]. In a second step, $\mathrm{Pb}$ is deposited at $150^{\circ} \mathrm{C}$. Finally, particles are embedded in a $\mathrm{SiO}_{\mathrm{x}}$ matrix to prevent oxidation during transfer from the vacuum system to the microscope.

Figure 1 displays the general appearance of the $\mathrm{Ga}-\mathrm{Pb}$ nanosystem as observed by TEM in the case of sample $\mathrm{E} 1: \mathrm{Ga}_{0.85} \mathrm{~Pb}_{0.15}$ corresponding to the successive deposition of layers of equivalent thicknesses: $3.2 \mathrm{~nm}$ for $\mathrm{Ga}$ and $0.8 \mathrm{~nm}$ for $\mathrm{Pb}$. We can easily distinguish the uniform contrast of $\mathrm{Ga}$ nanodrops and the diffraction contrast of $\mathrm{Pb}$ nanocrystals. The $\mathrm{Ga}$ nanodrops [7] size distribution is bimodal. In the main mode, whose size is about $20 \mathrm{~nm}$, we observe the presence of $\mathrm{Pb}$ crystals of about $8 \mathrm{~nm}$ in size. Many $\mathrm{Pb}$ crystals are in contact with the $\mathrm{Ga} / \mathrm{SiO}_{\mathrm{x}}$ inner surface while only some of them are in the center of the Ga droplet. In the second mode, the $\mathrm{Ga}$ nanodrops are small and polydispersed in size. In this case, the $\mathrm{Pb}$ nanocrystals are less visible due to their small size. High resolution observations demonstrate that no free solid $\mathrm{Pb}$ crystal is visible outside the Ga droplets.
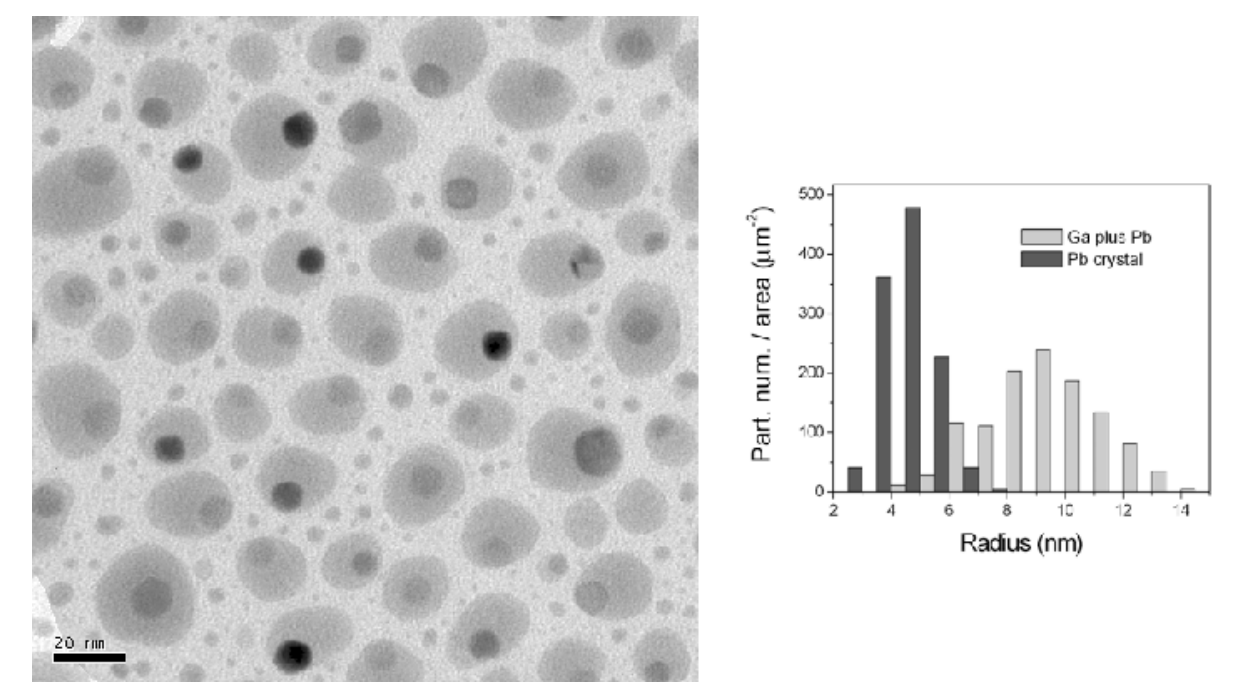

FIG. 1: Typical picture of a $\mathrm{Ga}-\mathrm{Pb}$ system (sample $\mathrm{E} 1: \mathrm{Ga}_{0.85} \mathrm{~Pb}_{0.15}$ ) at room temperature, obtained with bright-field TEM. Ga is liquid (uniform light grey) and $\mathrm{Pb}$ is solid (more or less dark depending on the orientation of the crystal, in Bragg conditions or not). On right, histogram of $\mathrm{Ga}$ and $\mathrm{Pb}$ sizes for the same sample (for clarity, Ga droplets of radius < $4 \mathrm{~nm}$ have not been considered).

A careful examination of the $\mathrm{Pb}$ nanocrystals shows faceted shapes. In the lower left corner 
of Fig. 1, we can observe 6 facets corresponding to the projection of the $\mathrm{Pb}$ cuboctaedron on the plane of the picture. One can easily note that the bigger the Ga droplets, the bigger the $\mathrm{Pb}$ crystals inside. The presence of nanodrops containing no $\mathrm{Pb}$ crystal is an exception that can be explained by a split of the Ga droplet before being covered by $\mathrm{SiO}_{\mathrm{x}}$.

More information on the relative shapes of the Ga droplets and the $\mathrm{Pb}$ crystals can be obtained by SEM provided larger particles are used. In Fig. 2 we give a secondary electron image showing the cross-section of $\mathrm{a} \mathrm{Ga}_{0.951} \mathrm{~Pb}_{0.049}(\mathrm{Ga} 25 \mathrm{~nm}+\mathrm{Pb} 2 \mathrm{~nm})$ sample on a silicon substrate which has been broken in order to reveal the profile of the droplets in a plane normal to the substrate. It is possible to measure the height and the apparent diameter of the Ga droplets in order to derive the contact angle $\theta$ of $\mathrm{Ga}$ on the SiOx substrate. The word "apparent" refers to the projection of the particle on the image plane. Such an analysis has been performed on two samples $\mathrm{Ga}_{0.951} \mathrm{~Pb}_{0.049}$ and $\mathrm{Ga}_{0.975} \mathrm{~Pb}_{0.025}(\mathrm{Ga} 25 \mathrm{~nm}+\mathrm{Pb} 2 \mathrm{~nm}$ and $\mathrm{Ga} 50 \mathrm{~nm}+\mathrm{Pb} 2 \mathrm{~nm})$.
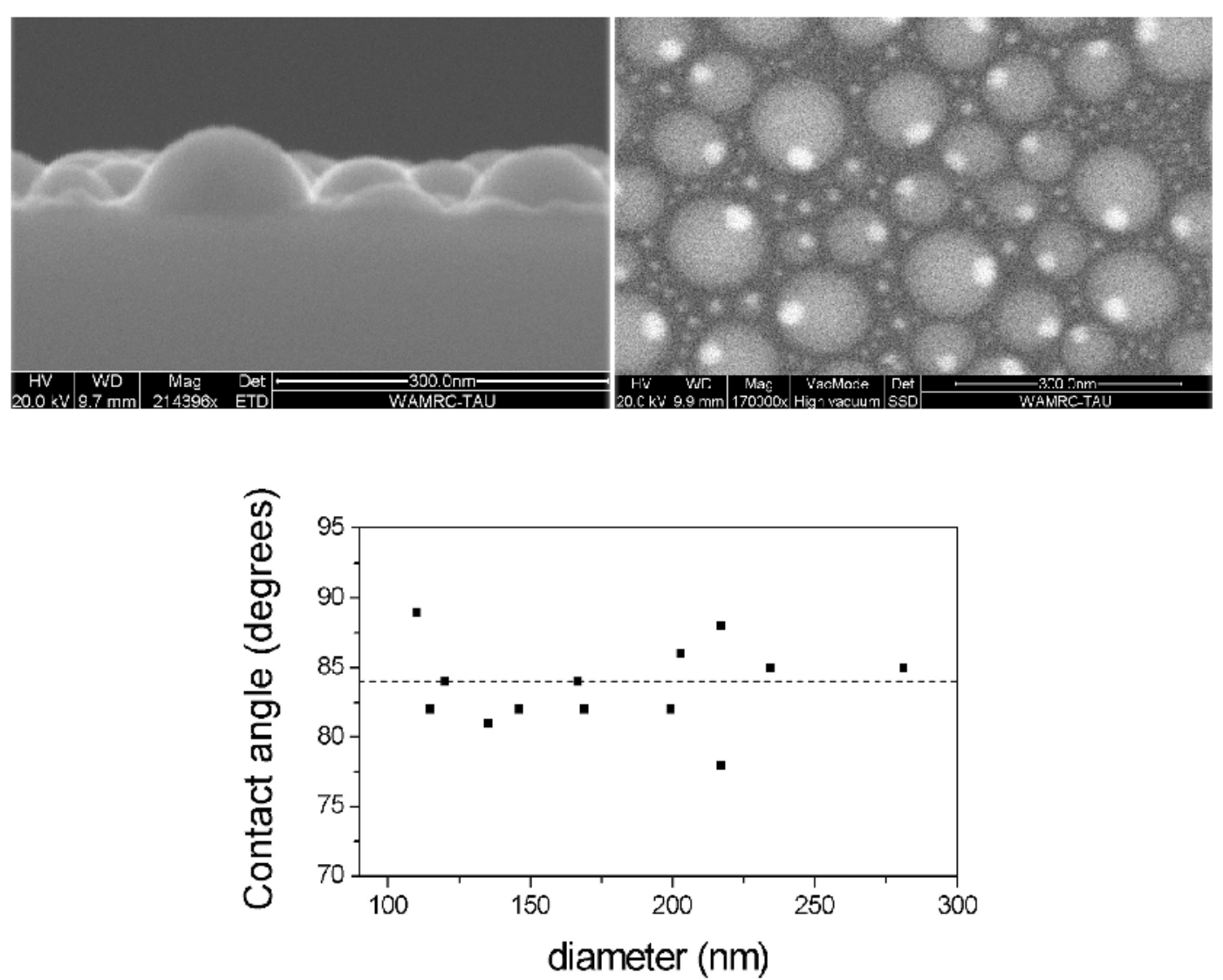

FIG. 2: Upper panel: SEM experiments: cross-section (secondary electron image) and planar view of the sample (back-scattered electrons image).

Lower panel: Contact angle on the $\mathrm{SiO}_{\mathrm{x}}$ substrate versus $\mathrm{Ga}$ nanodrops size (from cross-section SEM experiments)

As shown in Fig.2, we do not observe a size dependence of $\theta$. The average value of the contact angle of a nanodrop of $\mathrm{Ga}$ on $\mathrm{SiO}_{\mathrm{x}}$ is found to be $\theta=84^{\circ} \pm 2^{\circ}$.

Due to the higher signal of back-scattered electrons from $\mathrm{Pb}$ relative to $\mathrm{Ga}$, the back-scattered electron image in Fig. 2 reveals that $\mathrm{Pb}$ crystals exist in every droplet, even in the smallest ones. 


\section{Analysis of the two-components breath figure growth}

The growth mode of the Ga liquid breath figure is known [1-2]. Concerning $\mathrm{Pb}$, TEM and SEM observations show that all the $\mathrm{Pb}$ is inside the $\mathrm{Ga}$ droplets. For understanding the $\mathrm{Pb}$ growth it is necessary to analyse the relation between the $\mathrm{Ga}$ and $\mathrm{Pb}$ particle sizes.

The overall $\mathrm{Pb}$ concentration in a given $\mathrm{Ga}$ droplet has two contributions: the first one corresponds to $\mathrm{Pb}$ dissolved in liquid $\mathrm{Ga}$ : it is very small but unknown unless we accept the data of the bulk phase diagram [6] which indicates 0.02 at $\%$ at room temperature; the second one is obtained from the visible $\mathrm{Pb}$ rich solid phase. By analyzing the TEM pictures at room temperature, we can extract the $\mathrm{Pb}$ concentration due to this second contribution as a function of the Ga droplet radius (Fig. 3). A strong decrease of the $\mathrm{Pb}$ concentration with the $\mathrm{Ga}$ droplets size is observed. The horizontal dotted line corresponds to the concentration one would observe if $\mathrm{Pb}$ was uniformly distributed among the Ga particles.

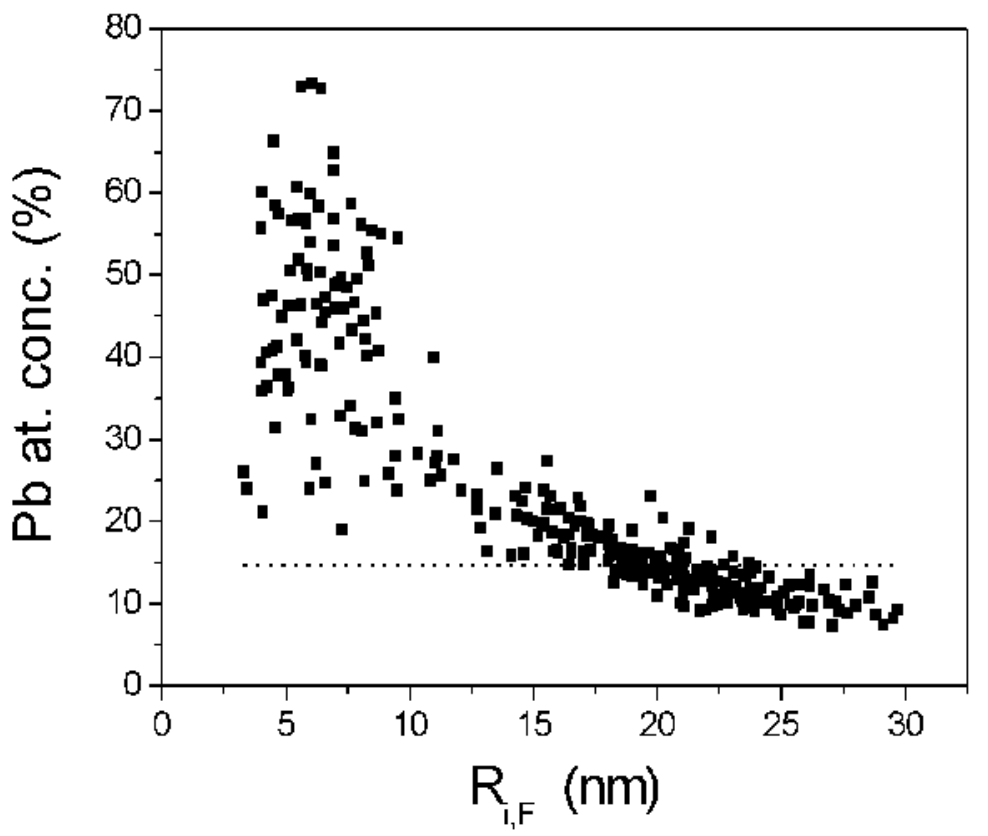

FIG. 3: $\mathrm{Pb}$ atomic concentration versus the apparent size of the Ga droplets in $\mathrm{Pb}_{0.147} \mathrm{Ga}_{0.853}$ sample. The dotted line corresponds to the average $\mathrm{Pb}$ atomic concentration

In order to explain this difference, we present a model that identifies how the $\mathrm{Pb}$ atoms share among the $\mathrm{Ga}$ droplets and therefore predicts the $\mathrm{Pb}$ concentration within each nanodrop. First we have analyzed a $\mathrm{Ga}$ breath figure to obtain the size distribution of the droplets versus the thickness $\left(\mathrm{d}_{\mathrm{Ga}}\right)$ of the equivalent Ga parallel film. The average apparent radius $\left\langle\mathrm{R}_{\mathrm{Ga}}\right\rangle$ of the droplets is given by $\left\langle\mathrm{R}_{\mathrm{Ga}}\right\rangle=2.48 \mathrm{~d}_{\mathrm{Ga}}$ in the limited size range of the sample [2].

An image analysis of TEM pictures permits to extract the sizes $r_{i}$ of the Pb crystals together with the sizes $R_{i}$ of the Ga nanodrops. For a given sample, the volumes $V_{i}^{\mathrm{Pb}}$ of $\mathrm{Pb}$ crystals are calculated in a spherical approximation while for $G$ a droplets the volumes $V_{i}^{G a}$ are calculated taking into account the contact angle $\theta$ of $\mathrm{Ga}$ on the $\mathrm{SiO}_{\mathrm{x}}$ substrate obtained in 
previous paragraph. This results in:

$$
V_{i}^{G a}=\frac{\pi R_{i}^{3}}{3 f}
$$

where $R_{i}$ is the apparent radius of the Ga droplet and $f=\frac{\sin ^{3} \theta}{2+\cos ^{3} \theta-3 \cos \theta}$.

The model, which describes the relation between $\mathrm{R}_{\mathrm{i}}$ and $\mathrm{r}_{\mathrm{i}}$, is based on some assumptions on the growing process: once the $\mathrm{Ga}$ breath figure is established, a uniform $\mathrm{Pb}$ atoms flux is sent on the sample and all $\mathrm{Pb}$ atoms enter into Ga droplets. This aggregation problem has been investigated (see [8] and references therein) and capture zones must normally be defined for determining which island receives a given atom. In the present case the problem is simplified by the fact that initial Ga droplets are known and have a fixed position. We therefore make two simple assumptions based on the two different ways a $\mathrm{Pb}$ atom reaches a $\mathrm{Ga}$ nanodrop:

i) the probability for $\mathrm{a} \mathrm{Pb}$ atom to directly arrive on a $\mathrm{Ga}$ droplet is proportional to the apparent surface of the Ga droplet.

ii) between the $\mathrm{Ga}$ droplets, the $\mathrm{Pb}$ atoms arriving on the bare $\mathrm{SiOx}$ substrate diffuse and finally incorporate in a $\mathrm{Ga}$ droplet. In this case its probability to enter a Ga droplet is proportional to the contact line length.

With such assumptions, it is possible to calculate the size of the $\mathrm{Pb}$ crystal inside each $\mathrm{Ga}$ droplet. In a period of time dt, the total volume of $\mathrm{Pb}$ arriving in the particle number $\mathrm{i}$ is the sum of the two previously defined contributions:

that can be written as:

$$
\mathrm{dV}_{\mathrm{i}}^{\mathrm{Pb}}=\mathrm{dV}_{\mathrm{i}}^{\mathrm{Pb}, \mathrm{dir}}+\mathrm{dV}_{\mathrm{i}}^{\mathrm{Pb}, \mathrm{diff}}
$$

$$
\frac{\pi}{f} R_{i}^{2}(t) d R_{i}=\left\{\pi R_{i}^{2}(t) \delta_{P b}+\beta R_{i}(t)\right\} d t
$$

where $\delta_{\mathrm{Pb}}$ is the atomic $\mathrm{Pb}$ deposition rate $\delta_{\mathrm{Pb}} \mathrm{t}_{\mathrm{F}}=\mathrm{d}_{\mathrm{Pb}}, \mathrm{t}_{\mathrm{F}}$ being the total $\mathrm{Pb}$ deposition time and $\beta$ a coefficient related to the size of the capture zone.

Integrating between initial (I) and final (F) times gives:

$$
f d_{P b}=R_{i, F}-R_{i, I}-\frac{\beta}{\pi \delta_{P b}} \ln \frac{\frac{\beta}{\pi \delta_{P b}}+R_{i, F}}{\frac{\beta}{\pi \delta_{P b}}+R_{i, I}}
$$

Summing over all nanoparticles the term on the right hand side of equation (3), we obtain the total deposition rate for $\mathrm{Pb}$ on the analyzed total surface $\mathrm{A}_{\mathrm{T}}$ at the time $\mathrm{t}$, that is equal to $\delta_{\mathrm{Pb}} \mathrm{A}_{\mathrm{T}}$. For $\mathrm{t}=\mathrm{t}_{\mathrm{F}}$, the final apparent radii $\mathrm{R}_{\mathrm{i}, \mathrm{F}}$ satisfy the following equation:

$$
\pi \sum_{\mathrm{i}} \mathrm{R}_{\mathrm{i}, \mathrm{F}}^{2}+\frac{\beta}{\delta_{\mathrm{Pb}}} \sum_{\mathrm{i}} \mathrm{R}_{\mathrm{i}, \mathrm{F}}=\mathrm{A}_{\mathrm{T}}
$$

For every TEM picture, the $\beta / \delta_{\mathrm{Pb}}$ ratio can be calculated, using measured values for $A_{T}$ and the sums of $\mathrm{R}_{\mathrm{i}, \mathrm{F}}$ and $\mathrm{R}_{\mathrm{i}, \mathrm{F}}{ }^{2}$ on all particles. 
Resolution of Eq. 4 gives the initial (i.e. without $\mathrm{Pb}$ ) apparent radius $\mathrm{R}_{\mathrm{i}, \mathrm{I}}$ of the Ga droplet $\mathrm{i}$, the final (i.e. with $\mathrm{Pb}$ ) apparent radius $\mathrm{R}_{\mathrm{i}, \mathrm{F}}$ being measured on the TEM picture.

It is then possible to obtain the size $\mathrm{r}_{\mathrm{i}}$ of the $\mathrm{Pb}$ crystal:

$$
4 f r_{i}^{3}=R_{i, F}^{3}-R_{i, I}^{3}(1+C)
$$

where $\mathrm{C}$ accounts for the small volume solubility of $\mathrm{Pb}$ atoms in the liquid $\mathrm{Ga}$.

On the Fig. 4, we compare the values of the radii $r_{i}$ of the Pb crystals measured by TEM with the ones calculated with the above model. Data are represented as a function of $\mathrm{R}_{\mathrm{i}, \mathrm{F}}$, the apparent size of the Ga droplets, also measured by TEM.

Fig.4a presents the results obtained for two samples with same $\mathrm{Ga}$ and different $\mathrm{Pb}$ contents while Fig. $4 \mathrm{~b}$ gives the results obtained for three samples with same $\mathrm{Pb}$ and different $\mathrm{Ga}$ contents.

Remember that the value on the ordinate axes in the graphs do not account for the total quantity of $\mathrm{Pb}$ in the particle, as can be seen in Eq. (6), but only for the part that is visible as a floating solid crystal of radius $r_{i}$ in TEM pictures. Due to a small amount of $\mathrm{Pb}$ atoms dissolved in $\mathrm{Ga}$, there is a nonzero value of the $\mathrm{Pb}$ average concentration in the sample for which there is not $\mathrm{Pb}$ crystal formation. This has been actually confirmed in a sample $\mathrm{Ga}_{0.9936} \mathrm{~Pb}_{0.0064}(\mathrm{~Pb}$ volume concentration $1 \%$ i.e. $\mathrm{Ga} 2 \mathrm{~nm}+\mathrm{Pb} 0.02 \mathrm{~nm})$ for which there was no evidence of solid cores in HREM images.

\section{Discussion}

The first question raised by TEM observations is: why is the $\mathrm{Pb}$ crystal inside the $\mathrm{Ga}$ droplets ? The surface energies of $\mathrm{Ga}$ and $\mathrm{Pb}$ are known: $\gamma_{\mathrm{Ga}}=690 \mathrm{~mJ} / \mathrm{m}^{2}$ and $\gamma_{\mathrm{Pb}}=610 \mathrm{~mJ} / \mathrm{m}^{2}$ (see, for instance, [9]); in the lack of more data, we can approximate that interfacial energies $\gamma_{\mathrm{Ga} / \mathrm{SiO}}$ and $\gamma_{\mathrm{Pb} / \mathrm{SiO}}$ are respectively not very different than the surface energies $\gamma_{\mathrm{Ga}}$ and $\gamma_{\mathrm{Pb}}$. Concerning the interfacial energy $\gamma_{\mathrm{Ga} / \mathrm{Pb}}$, it is not known but is certainly much weaker. We are therefore in the situation $\gamma_{\mathrm{Ga} / \mathrm{SiO}}+\gamma_{\mathrm{Pb} / \mathrm{SiO}}$ ? $\gamma_{\mathrm{Ga} / \mathrm{Pb}}$, described by Hagege and Dahmen [4], which excludes the possibility to have $\mathrm{Ga}$ and $\mathrm{Pb}$ isolated particles. Moreover, as $\gamma_{\mathrm{Ga} / \mathrm{SiO}}$ and $\gamma_{\mathrm{Pb} / \mathrm{SiO}}$ are not very different one from the other, the same authors predict a microstructure, in the particles, where both components are separated in two parts $\mathrm{Ga}$ and $\mathrm{Pb}$ with a plane separation. We observed that situation is more complex because it depends on temperature. A more detailed analysis will be reported in another paper [10]. 

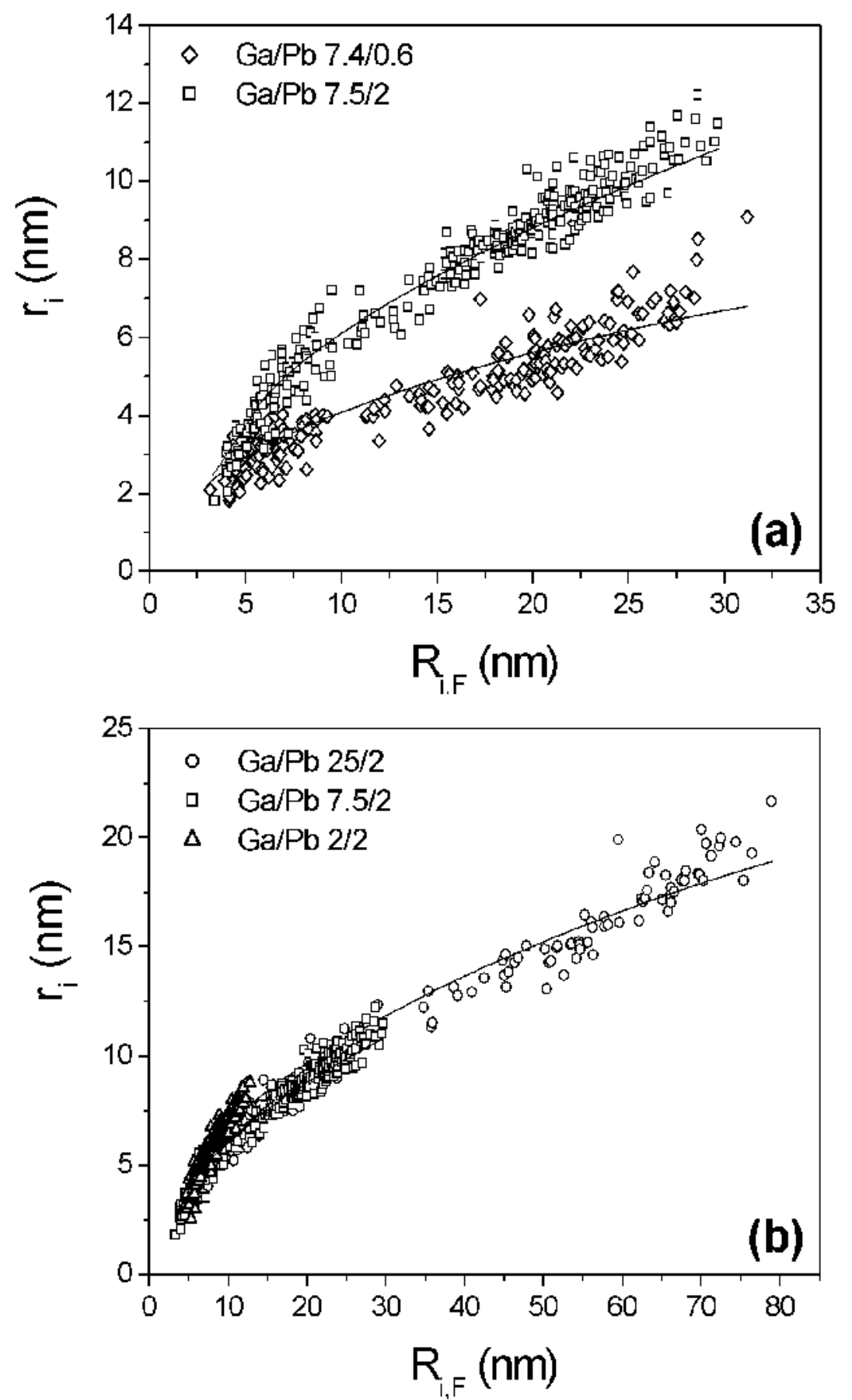

FIG. 4: The radius $r$ of the $\mathrm{Pb}$ crystal (with spherical approximation) versus the apparent radius $R_{F}$ of its embedding $\mathrm{Ga}$ droplet. The symbols correspond to experiments listed in the following table. In the model (solid line), the volume solubility of $\mathrm{Pb}$ in $\mathrm{Ga}$ is $\mathrm{C}=1 \%$.

\begin{tabular}{|c|c|c|c|c|c|c|}
\hline Sample name & $\begin{array}{c}\text { picture } \\
\text { symbol }\end{array}$ & $\begin{array}{c}\text { Pb Volume Conc. } \mathrm{C}_{\mathrm{Pb}} \\
(\%)\end{array}$ & $\begin{array}{c}\mathrm{d}_{\mathrm{Pb}} \\
(\mathrm{nm})\end{array}$ & $\begin{array}{c}\mathrm{d}_{\mathrm{Ga}} \\
(\mathrm{nm})\end{array}$ & $\begin{array}{c}\text { Area } \mathrm{A}_{\mathrm{T}} \\
\left(\mu \mathrm{m}^{2}\right)\end{array}$ & $\begin{array}{c}\text { Surface } \\
\text { coverage }\end{array}$ \\
\hline $\mathrm{D} 7: \mathrm{Ga}_{0.95} \mathrm{~Pb}_{0.05}$ & $\diamond$ & 7.5 & 0.6 & 7.4 & 0.337 & 0.577 \\
\hline $\mathrm{C} 4: \mathrm{Ga}_{0.853} \mathrm{~Pb}_{0.147}$ & $\mathrm{~V}$ & 21.1 & 2 & 7.5 & 0.547 & 0.551 \\
\hline $\mathrm{A} 8: \mathrm{Ga}_{0.951} \mathrm{~Pb}_{0.049}$ & $\mathrm{~d}$ & 7.4 & 2 & 25 & 1.267 & 0.629 \\
\hline $\mathrm{A} 6: \mathrm{Ga}_{0.61} \mathrm{~Pb}_{0.39}$ & $\mathrm{~V}$ & 50 & 2 & 2 & 0.113 & 0.369 \\
\hline
\end{tabular}


We obtain a satisfactory agreement between our simple model and the experimental results. As can be seen in Fig. 4, this good agreement is found without any free parameter. It is important to note that the $\mathrm{Pb}$ solubility $\mathrm{C}$ in Ga has been determined in accordance to our hypothesis that all $\mathrm{Pb}$ atoms are incorporated on $\mathrm{Ga}$ droplets. The values obtained are roughly one order of magnitude larger than the one given by the bulk phase diagram. We suppose that this disagreement is due to a size effect and is presently investigated.

We present in Fig. 5 the dependence between the surface coverage (i.e. the fraction of the sample covered by nanoparticles) and the mean radius of the nanodrops. We recover the same behavior than the one obtained for a classical one-component breath figure [1-2]. The saturation for the larger $R_{i, F}$ values is due to the coalescence processes giving rise to the breath figure geometry. For the lower $\boldsymbol{R}_{i, F}$ values, it is important to note that the geometric structure is qualitatively different. This is of great importance when trying to estimate which one of the two possible incorporation processes considered in the model is dominant. In other words, the ratio between the two terms appearing in Eq. (5) is strongly affected by the geometric structure of the system.

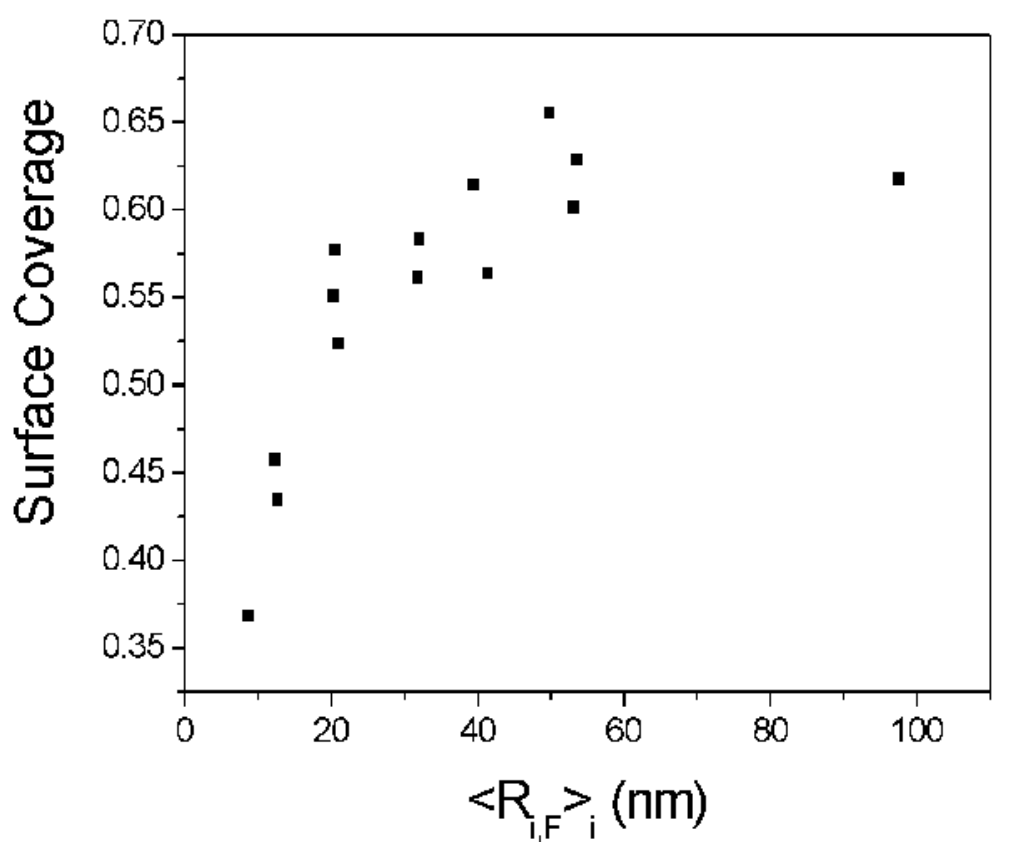

FIG. 5: Surface coverage versus average droplet apparent radius for the Ga-Pb samples investigated.

This is illustrated in Fig. 6 where we represent the probabilities $p_{i, 1}$ and $p_{i, 2}$ for an atom to be absorbed respectively directly or after diffusion on the substrate as a function of the particle radius $\boldsymbol{R}_{i, F}$. These probabilities are built using Eq. (3) applied to an experimental distribution of radius $\boldsymbol{R}_{i, F}$ presented in the inset. Since we considered that an incident $\mathrm{Pb}$ atom is incorporated into one of the existing Ga droplets, the normalization constraint implies 
that :

$$
\sum_{i}^{N}\left(p_{i, 1}+p_{i, 2}\right)=1
$$

where $\mathrm{N}$ is the number of $\mathrm{Ga}$ droplets. We can see that the two processes have almost the same importance for particles with radius roughly smaller than $15 \mathrm{~nm}$. A direct impingement becomes the main process for larger particles. As discussed above, this cross-over is directly associated to the geometric structure of the Ga breath figure. A different geometric structure (e.g. a different radius distribution or a long-ranged correlation between particle centers of mass) would strongly influence the transition between the two regimes.

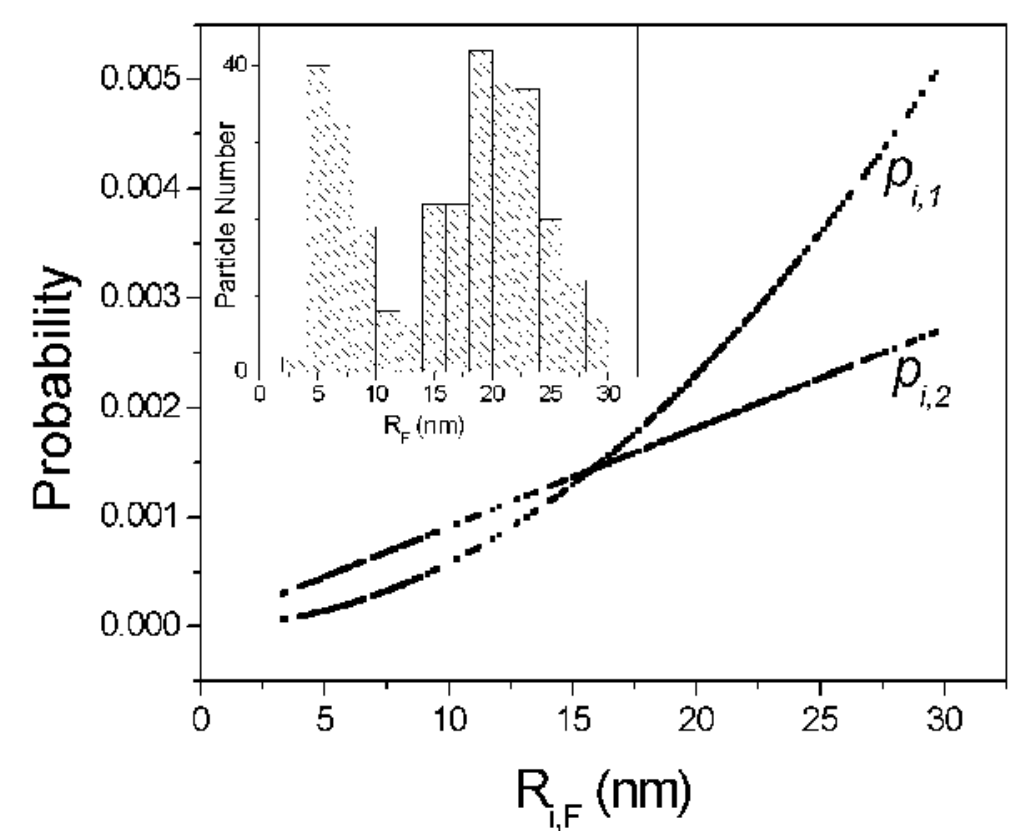

FIG. 6: The probabilities $p_{i, 1}$ and $p_{i, 2}$ for an impinging $\mathrm{Pb}$ atom to enter a Ga nanodrop of radius $R_{i, F}$ directly or after diffusion respectively.

\section{Conclusion}

In this paper, we have demonstrated that it is possible to grow nanocrystals inside a different non-interactive liquid phase if both materials are immiscible. In the present study each Ga nanodrop behaves like a nano-container inside which the $\mathrm{Pb}$ crystallization occurs.

For this purpose we have developped a technique which appears suitable: the two-components breath figure. We have identified two distinct growth regimes depending on the way the solute atoms are incorporated in the nanodrop. If the $\mathrm{Pb}$ atoms directly reach the nanodrop, we expect a scaling of the concentration as $\mathrm{R}^{-2}$, while if the $\mathrm{Pb}$ atoms touch the substrate, the expected scaling is $\mathrm{R}^{-1}$. A cross-over between these two regimes should occur as a function of the mean radius but also of the structuration of the Ga nanodrops. 


\section{$\underline{\text { References: }}$}

* Corresponding author: kofman@unice.fr

[1] P. Meakin, Rep. Prog. Phys. 55, 157 (1992)

[2] E. Søndergard, R. Kofman, P. Cheyssac and A. Stella, Surface Science 364, 467 (1996)

[3] T. Ben-David, Y. Lereah, G. Deutscher, J.M. Penisson, A. Bourret, R. Kofman and P. Cheyssac, Phys. Rev. Lett. 78, 2585 (1997)

[4] S. Hagege and U. Dahmen, Phil. Mag. Lett. 74, 259 (1996)

[5] A. Defrain, J. Chim. Phys. 74, 851 (1977)

[6] I. Ansara and F. Ajersch, J. Phase Equilibria 12, 73 (1991)

[7] L. Haderbache, R. Garrigos, E. Søndergard, R. Kofman and P. Cheyssac, Surface Science 410, L748 (1998)

[8] A. Zangwill, Nature 411, 651 (2001)

[9] B. Pluis, D. Frenkel and J.F. van der Veen, Surface Science 239, 282 (1990)

[10] M. Allione, R. Kofman, F. Celestini and Y. Lereah, Eur. Phys. J. D 52 (2008) 279 